https://doi.org/10.48009/2_iis_2009_451-458

\title{
SIX SIGMA MEET INFORMATION SYSTEMS
}

\author{
Roger L. Hayen, Central Michigan University, roger.hayen@cmich.edu
}

\begin{abstract}
This research examines a relationship between Six Sigma methodology and a business problem that emerges with an information technology (IT) solution as the best alternative. A knowledge set of Six Sigma is compared to the content of the systems analysis and design $(S A \& D)$ and accounting information systems (AIS) courses typically offered by colleges of business. The purpose is to identify potential areas whereby there is a match between Six Sigma and these IT courses. Six Sigma and IT touch points range from Six Sigma IT tools supported by IT to a Six Sigma result that is achieved by an IT solution. When IT is included in the solution, the Six Sigma project may take a detour (identified herein as a "speed bump") while the IT solution is prepared and implemented. An advantage of an IT solution is that control is instantiated that makes it very difficult to deviate from the new solution. Six Sigma and traditional IT business problem solutions share many techniques that are compatible with one another. Where these intersections occur, IT courses can include a Six Sigma view to better prepare future systems analyst to work in this environment. The Six Sigma and IT synergies should undergo further examination to provide additional direction on how these two methodologies can better support future IT education.
\end{abstract}

Keywords: Six Sigma, Systems Development, Systems Implementation, Systems Analyst

\section{INTRODUCTION}

Business problems or opportunities do not wear labels: "I'm an IT problem" or "I'm an operating process problem." Life would be so much easier if business problems were required to come pre-labeled. However, they are just generic business problems that must be sized up and then tackled with an appropriate solution. Six Sigma is this kind of general business problem solving approach. Ever since its conception at Motorola in the mid 1980's, Six Sigma programs have grown by leaps and bounds worldwide [1, 2, 3]. Some Six Sigma projects may lead to an IT solution; however, every Six Sigma project does not have such an IT solution. A typical Six Sigma project is initiated without any predisposed predilection of an IT solution. Rather, Six Sigma methodology provides a very robust tool set for addressing business problems or opportunities in order to formulate a best solution. The purpose here is not to review all the possible tools of Six Sigma methodology, but rather to show how a core set of these tools are available for addressing a business problem that happens to culminates in an IT solution. Here, the Six Sigma process itself leads to an IT solution as the preferred alternative. Six Sigma focuses on the process owner (the customer) by listening to the needs of that owner and then making improvements to the process [5]. A different project may apply other selected tools from among those used with the Six Sigma project toolkit. And, the project could lead to a change in manual business processes rather than an automated solution. Because IT projects may be initiated from a Six Sigma analysis, it is important for information professional to have an understanding of the Six Sigma approach. This understanding allows them to leverage the Six Sigma analysis, which has been completed, as they embark on the spin-off IT project.

The purpose of this research is to develop and support a symbiotic framework between the methodology of Six Sigma and IT development including the preparation of entry level system analysts. Six Sigma methodologies provide a robust tool set for tackling business problems. Many times the solutions to these problems do not lead to an IT solution. However, an IT solution is always on the table as one potential solution for many business problems. The results are present as an overview of the Six Sigma process, IT solutions, and IT education preparation (Figure 1).

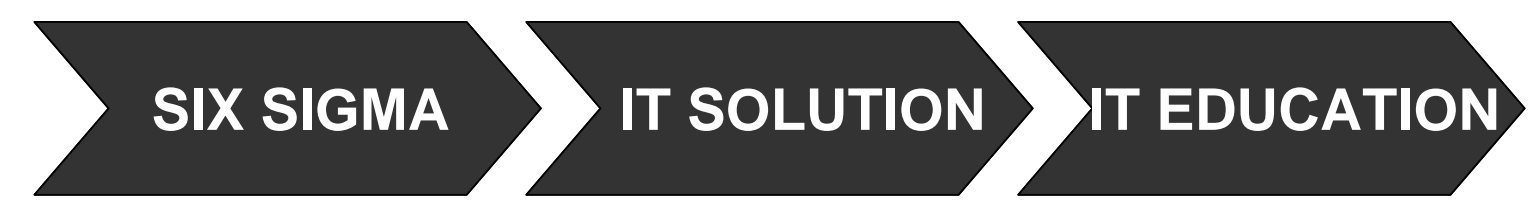

Figure 1: Six Sigma and IT 


\section{SIX SIGMA METHODOLOGY}

The core of Six Sigma is relentless problem solving. Typically $[6,14]$, the Six Sigma methodology is arranged as the five phases: define, measure, analyze, improve, control (DMAIC). The phases are utilized to guide a Six Sigma project and provide a foundation for deploying its methodology. The phases are summarized here to reinforce their common and generally accepted content in including an intersection point with IT.

- Define - Identify the project opportunities, select and prioritize projects, and draft the project charter. The business opportunity is frequently identified by a local champion, who is a manager in the business unit where the opportunity has surfaced as an important business issue, which is likely not identified immediately as an IT opportunity.

- Measure - Identify the key internal process that influences the critical to quality (CTQ) characteristics. Then, identify the key output variables so that the capability of the current process can be determined. This is an end-to-end process measurement. When the business opportunity does become an IT opportunity, this is likely to include all the elements of the process, which surround an IT solution - both automated and manual.

- Analyze - Understand the root causes driving the defects. Brainstorming, prioritization, and statistical validation tools are used to identify key variables that cause the defects. This is a data-driven evaluation. The output of this phase is the identification of the variables that drive the process variation the most. These variables become the focus for the solution. If an IT solution is to emerge, it must address these process variables.

- Improve - Confirm the key variables and then quantify the effect these variables have on the CTQs, identify the maximum acceptable ranges of the key variables, make sure the measurement systems are capable of measuring variations in the key variables, and modify the process to stay within acceptable ranges. It is here that an IT solution may emerge as the best solution. The IT project becomes the focus for the Six Sigma solution and that IT solution is developed and implemented.

- Control - Ensure that the modified process now enables key variables to stay within the maxi- mum acceptable ranges, using tools such as statistical process control (SPC) or simple checklists. This relies on measuring the CTQs for the deployed solution. When an IT solution is the primary remediation of the Six Sigma project, that solution will likely provide an environment which impedes regression to the original process. Hence, the IT solution is likely to provide robust control.

A Six Sigma project team follows these phases in carrying out their project; however, each project is unique. Although the desired duration of a Six Sigma projects is targeted on six to nine months [6], some are likely to take longer. This is particularly the situation that may occur with a Six Sigma project wherein the process is improved with an IT solution. Other Six Sigma projects that require the acquisition of a new piece of manufacturing equipment or modifications to such equipment may also experience similar loss of project control. However, the focus here is limited to IT solutions.

While each Six Sigma project is expected to follow the DMAIC phases, the duration of each phase is fluid and varies depending on the situation encountered in a particular project. The Six Sigma methodology encompasses a very large group of tools that support carrying out the project. Hence, each Six Sigma project team, under the leadership of the project's black belt, is expected to select those tools which provide appropriate support for their project. While some tools will be used with most projects, others will not be used so frequently. This is recognition that each project is unique and takes on its own personality. An important component of Six Sigma black belt and green belt training is preparing team members so they understand what is in a typical Six Sigma toolbox for their use $[6,7,8,9,10]$.

\section{INFORMATION TECHNOLOGY SOLTUION}

Several Six Sigma interactions may occur with information systems (IS) or information technology (IT). These include (1) the support of any Six Sigma project with IT, (2) a Six Sigma project which results in an IT solution, or (3) a Six Sigma project in which an existing IT solution is improved by changing manual processes, which surround that solution (Figure 2). It is important to distinguish between computer-based Six Sigma tools and a Six Sigma project that results in an IT solution. Computerbased Six Sigma tools are typically provided and supported on a desktop platform throughout an organization, and hence IT staff provides and supports these tools, such as Excel, a Six Sigma calculator, and many others reported by Hsieh, Lin, and 
Manduca [14]. An IT solution is one where software provides the core change for improving the processing, such as those reported by Hayen [13] and in "Sustain the Gain" [19]. During the data-driven, five-phased approach of Six Sigma, an IT solution emerges as the best method for mitigating the business problem with an improved process. Then, the IT solution instantiates a robust control arrangement, because it removes old ways of carrying out these business processes. This elimination, or "burning bridges," insures the continuation of the new process forever (which in Six Sigma is until there is a major change in how business is conducted and that may trigger another Six Sigma project).

A variety of IT or computer-based tools (Figure 2 A) are described which provide for both the support of data collection and data analysis [14]. These tools assist with the calculation of the sigma level and statistical data analysis. Statistical analysis is especially important, because the Six Sigma process is datadriven. Hence, the analyzed data provide direction in determining the root cause of a business problem, which is then improved through Six Sigma processes. Six Sigma projects which result in an IT solution (Figure $2-$ B) are described by Hayen [13] and in "Sustain the Gain" [19]. In both projects, the improved solution was an IT solution to the Six Sigma business problem. That is, the Six Sigma process lead to the best solution, which was to apply IT in creating the improved process.

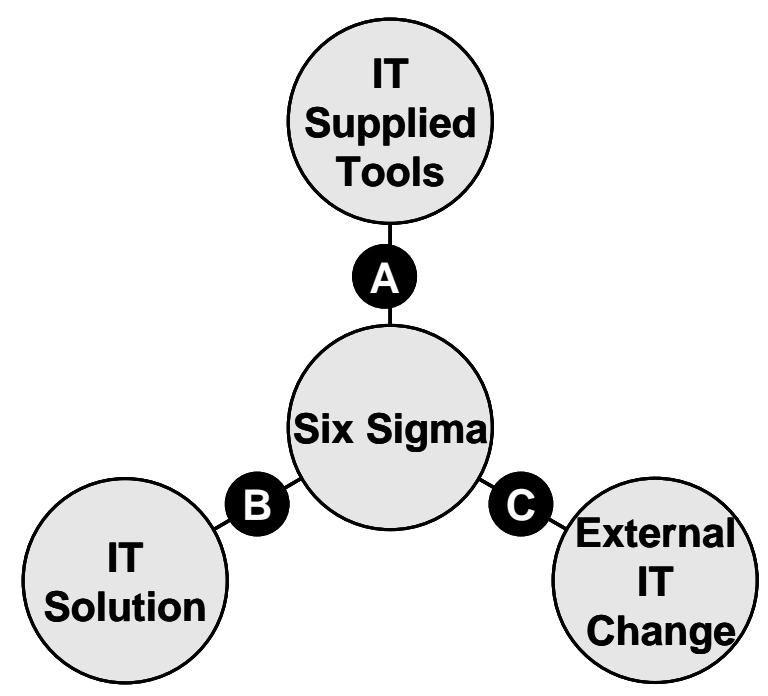

Figure 2: Six Sigma touch points with IT

Six Sigma projects in which an existing IT was improved by changing manual processes (Figure 2 C) are described by Benedetto [4] and Drickhamer
[11]. In the first instance, manual processes in retrieving radiology films from a library were described. This involved changes in the standard operating procedures (SOP) for requesting these films and routing them to the appropriate location. In the second instance, the Canada Post changed many of the mail handling processes to provide better performance. Canada Post had upgraded to the SAP Enterprise Software prior to their Six Sigma project. Their Six Sigma project occurred sometime after the implementation of the SAP software had been completed. Hence, this Six Sigma project did not drive the acquisition of the SAP software; rather it was mutually exclusive from the SAP acquisition decision. However, the integrated design of the SAP software provided an IT environment that subsequently supported the re-design of the manual mail processing steps at Canada Post. The capabilities of the SAP software supported their improvements. This would not have been possible with their legacy software, which the SAP software replaced. Overall, Six Sigma has several very different touch points with IT, which provide quite dissimilar interactions between them. Clearly, there is not one all encompassing, single view of such interactions.

\section{Implementation "Speed Bump"}

A "speed bump" is a challenge that interrupts an implementation [13]. A speed bump is like a major detour during road construction. It is similar to a "black hole" into which the Six Sigma project enters until the IT solution has been implemented. A speed bump results in shifting direction from a Six Sigma project to an IT project for the procurement and installation of the selected software solution (Figure 3). Once remediation is determined to be a software solution; the Six Sigma project interfaces with the IT project. That is, the actual acquisition and installation of the software solution requires requesting IT resources for implementation. Until this point in the project, control of the project is with the process owner and the other members of the Six Sigma project team. When the software implementation shifts to the IT staff as one of their projects, then resources are allocated and tasked for that implementation. Project control shifts to the IT services organization. This is a noteworthy deviation in conducting a typically Six Sigma project, wherein it is expected the Six Sigma team controls the resources, end-to-end, required for the entire process including implementation [6]. However, a speed bump is a reality of a Six Sigma project, especially, where the best solution emerges as computer automaton (Figure $2-\mathrm{B}$ ). This was a lesson learned with Six Sigma projects. Such a project redirection was not presented as a Six Sigma 
project occurrence during Six Sigma black belt training [6]. In training, the entire project is viewed as under the control of the project team. Had the solution manifest itself as revisions to a manual process, which it could have, then this speed bump impediment would not occur in the Six Sigma project. A speed bump becomes part of project implementation whenever the control of implementation resources falls outside the direct management scope of the project team. Speed bumps are a reality of Six Sigma projects and must be anticipated by the process owner and other project team members.

\section{Framework}

A framework for Six Sigma project risk with IT solutions is founded on the extent of the nature of the proposed IT solution undertaken in the Improve phase. This solution may fall inside or outside of the automated portion of the IT. The part inside is the portion of the IT, which represents the direct computer processing (Figures 2 and $3-\mathrm{B}$ ). The segment outside is the group of manual processes, which supply data to or use data from the automated system (Figures 2 and $3-\mathrm{C}$ ). These are the human actions and interface with the automated IT. In general, the outside elements are ones, which may be improved under the direct control of the Six Sigma project team. On the other hand, the inside elements are ones which frequently fall outside of the direct control of the Six Sigma project team. An improved Six Sigma solution that requires changes to the inside elements are likely to require the involvement of the IT staff (Figures 2 and $3-\mathrm{B}$ ). This is where a speed bump, detour occurs. The extent of the IT project is likely to depend on the delays that are encountered in scheduling and conducting the IT project. Whereas small projects may receive nearly immediate IT resources, large projects are much more likely to require additional approvals, budgets and scheduling by the IT staff. While this is taking place, the direct control of the Six Sigma project is relinquished to the IT staff. This is the reality of Six Sigma projects with an IT solution. The Six Sigma project team should be prepared for a shift in control during the Improve phase when the solution is IT based.

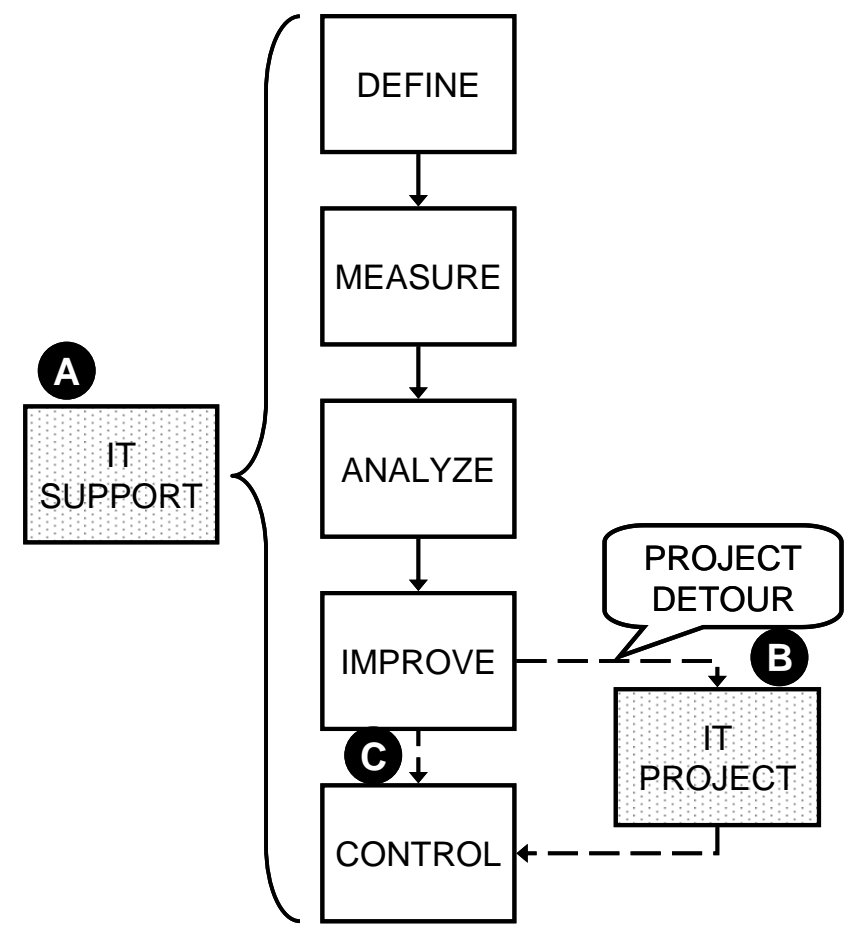

Figure 3: IT meets Six Sigma

\section{EDUCATION PREPARATION}

Clearly, the Six Sigma methodology may be deployed in addressing a business problem or opportunity that results in an IT solution. As a result, future IT education should consider the inclusion of appropriate Six Sigma methodology. For some IT concepts, this may mean incorporating Six Sigma terminology were it may readily align with current IT concepts included in these courses. For some courses, this may mean adding Six Sigma methodology to IT concepts where there this a good match between the business problem solving approach of Six Sigma and the current methods of IT systems development. This seems to be both a challenge and opportunity for the future of IT education.

The system development life cycle (SDLC) is included in many courses, such as those by Siau [17] and Sauter [15]. The SDLC typically has problem recognition, or a similar name, as the first SDLC phase. It is here where the problem or opportunity is identified. However, this typically focuses on problem recognition whereby the problem is likely to be addressed using IT. That is, the aim of deploying a Six Sigma project is targeted on an IT solution from its initiation. Otherwise, it is less likely to be of interest to an organization's IT department. Six Sigma is a more encompassing business problem solving approach that goes far beyond IT solutions, while still leading to some improvements, which are IT solu- 
tions. That is, Six Sigma is often a precursor to the SDLC. It is here where a Six Sigma project leads to an IT project. Because of the symbiotic relationship to business problems solving, Six Sigma methods and tools should be understood by an organization's IT staff. A number of the tools and techniques are in fact very similar. However, the approach and technical nomenclature may be different. In preparing students who will be future systems analysis, it is important that they understand this relationship between Six Sigma and IT approaches. A compelling reason is the ongoing adaption of Six Sigma as a general business problem solution methodology. End users of IT applications are likely to be involved with Six Sigma projects. Hence an alignment between Six Sigma and IT methods is most appropriate. On the one hand, this may be little more than an alignment of terminology, and on the other hand, this may be the inclusion of some tools which have not been included previously in IT courses. Then there are those situations whereby early SA\&D tools, such as those described by Semprevivo [16], may have been phased out. One means of providing alignment to future systems analysts is to include the tools and techniques of Six Sigma in IT systems analysis and design (SA\&D) courses and in accounting information systems (AIS) courses. Why AIS courses? This category is included, because the SDLC is a significant component of studies in this course and, hence, it includes many of the same topics as a SA\&D course with an overlapping IT focus.

So, the question for IT education is: How well are IT students prepared in the tools used with Six Sigma projects? One way of addressing this question is to examine the extent of the inclusion of Six Sigma tools in SA\&D and AIS courses. A means of measuring that inclusion is to determine the extent to which these Six Sigma methodology tools are included in current textbooks. How can this be measured? One approach is to review currently used textbooks for Six Sigma tool content. This is the approach taken here.

The extent of integration into leading information SA\&D and AIS textbooks were analyzed to determine whether or not they include Six Sigma tools and methods. That is, using a Six Sigma perspective for this analysis, "what do the numbers say" about this course integration? Key Six Sigma topics related to systems and analysis and design [7, 8] are listed in Table 1. This toolkit is drawn from a diverse universe of Six Sigma methods and tools. They have been successfully deployed for a number of years and have produced substantial and documented saving for the company.
Table 1: Six Sigma Tools and Methods

\begin{tabular}{|l|l|}
\hline Hidden factory & $\begin{array}{l}\text { Value added/non-value } \\
\text { added }\end{array}$ \\
\hline Risk management & Project charter \\
\hline Document flowchart & Defect \\
\hline Defect per opportunity & $\begin{array}{l}\text { Defect per million } \\
\text { opportunities (DPMO) }\end{array}$ \\
\hline Measurement plan & Root cause \\
\hline Sigma value & Cycle time reduction \\
\hline A delta T & $\begin{array}{l}\text { Cost-Time Profit } \\
\text { Analysis/Cost Benefit }\end{array}$ \\
\hline Opportunity statement & Brainstorming \\
\hline Morphological box & $\begin{array}{l}\text { Risk-Benefit } \\
\text { Analysis/Risk } \\
\text { Analysis/Benefit Analysis }\end{array}$ \\
\hline
\end{tabular}

Amazon.com is a widely accepted source of currently available textbooks on systems analysis and design. As reported by Stone [18], Amazon.com is the world's largest online retailer with nearly $\$ 15$ billion in annual sales in 2007 and is one of the iconic companies of the Internet era. It was founded in 1994 by Jeffrey P. Bezos as an online bookstore, which carries a diverse selection of currently available books, including textbooks. However, books were just the beginning. Amazon has recently expanded its business in several dimensions. In addition to selling physical media like CDs, DVDs and books, it sells digital copies of these products as well. Amazon maintains an overall highly regarded reputation for good prices, broad selection and convenience. Therefore, the Amazon textbook database provides a rich and robust sample of textbooks available on Six Sigma, SA\&D and AIS. This database is used to assess directions in the integration of Six Sigma into these IT courses.

The data set analyzed is the sample of all the textbooks available through Amazon.com. The Amazon.com data set was mined by performing a query for each of the three categories of textbooks: Six Sigma, SA\&D, and AIS. This was performed across the list of 18 commonly used Six Sigma tools (characteristics) set forth in Table 1. A number of queries were conducted on this data set in order to redact data related to Six Sigma and its inclusion in these textbooks.

A query of the topic Six Sigma produced 655 items. The query for systems analysis and design (SA\&D) yielded 392 items, whereas accounting information systems (AIS) generated 187 items. However, many of those items included results such as electrical power systems analysis [12]. These are not textbooks typically used in a business SA\&D course. Further, 
the data needed to be refined so the results included only those textbooks which focus on business for SA\&D and for AIS. Under textbooks, Amazon.com provides a variety of subcategories for narrowing a content search. While there is no specific business SA\&D subcategory, there is a computers and internet subcategory. This category was combined with the keyword "business" to provide a reduced set of textbook with a specific focus on business SA\&D. The result was a set of 45 textbooks. The redacted list was reviewed to insure their content aligned with that for SA\&D courses. In a similar manner for AIS, the business and investing subcategory was found to generate a list of textbooks with the most appropriate content for an AIS course. This set was further reduced by using the key word "business" to yield a list of 44 items with the most appropriate content.

The research methodology was to obtain the frequency of occurrence of each of the $18 \mathrm{Six}$ Sigma characteristics (Table 1) in the reduced sample of textbooks. The frequency of characteristic occurrence was obtained for each of the three textbook categories. The underlying hypothesis is that if Six Sigma tools are included in SA\&D and AIS courses, then the relative occurrence of the overall Six Sigma characteristics should be that same among textbooks in each of the three categories of Six Sigma, SA\&D and AIS.

The overall content hypothesis is tested for the equality of the proportion of occurrences of each of the characteristics among the three categories of textbooks. That is,

$$
\begin{aligned}
& \mathrm{H}_{0}: \mathrm{p}_{\text {Six Sigma }}=\mathrm{p}_{\mathrm{SA} \& \mathrm{D}}=\mathrm{p}_{\mathrm{AIS}} \\
& \mathrm{H}_{1}: \text { not all } \mathrm{p}_{\mathrm{i}} \text { are equal }
\end{aligned}
$$

The proportion of occurrences was used to standardize the data, because of the differences in the sample sizes of the data sets across the three categories. That is, the proportion of the occurrences is expected to be the same, regardless of the frequency of occurrence of a characteristic within a category. If these appropriate Six Sigma characteristics have been included in SA\&D and in AIS, then these proportions of occurrences should, in deed, be equal. If they are not equal, then differences may be identified.

A paired-comparison test was used to determine if the proportion of occurrence where equal. The results are shown in Table 2. These results are also supported by the non-parametric Wilcoxon SignRank test.
Table 2: Significance of Categories across All Characteristics

\begin{tabular}{|l|l|l|}
\hline Category Pair & $|\mathbf{t}|$, probability & $\begin{array}{l}\text { Significant at } \\
\mathbf{0 . 0 5} \text { p-Value }\end{array}$ \\
\hline SA\&D - AIS & 0.6189 & No \\
\hline $\begin{array}{l}\text { SA\&D - Six } \\
\text { Sigma }\end{array}$ & 0.0016 & Yes \\
\hline AIS - Six Sigma & 0.0039 & Yes \\
\hline
\end{tabular}

The results (Table 2) lead to the conclusion there is no difference in the overall extent of inclusion in Six Sigma characteristics between SA\&D courses and AIS courses. However; these courses do not include Six Sigma characteristics to the extent they are presented in Six Sigma textbooks, which does not come as a surprise, but rather, provides metrics that delineate the similarities and differences.

On the other hand, these results do indicate a potential deficiency in the inclusion of these topics in SA\&D and AIS courses. If data mining had produced greater proportions for these tools, then the inequality of the proportions between the Six Sigma contents and the SA\&D or AIS content would have been even greater. This indicates that a number of Six Sigma tools used within major businesses are not even included in those textbooks. It represents an opportunity for future Six Sigma textbooks, as well as an opportunity for inclusion in SA\&D and AIS courses.

A review of the individual characteristics indicates a number of them where the proportions across the three areas are nearly equal. Others portray noteworthy differences, while some categories show limited inclusion even within the Six Sigma tools. That is, a number of the Six Sigma tools do not align with their importance as used by larger corporations as indicated by Dow $[6,7,8,9,10]$ and as set forth in the case study by Hayen [13]. Figure 4 illustrates these variations.

Characteristics found to have a strong alignment with Six Sigma are:

- Value added/non-value added

- Risk management

- Risk/benefit analysis

Further data mining revealed that, while the characteristic value added was similar across the three categories, this did not hold for the related characteristic of non-value added. Non-value added did not occur within SA\&D or AIS. This characteristic is very important, because it surfaces processes which are 
prime candidates for elimination. Elimination is key in improving the efficiency of business processes.

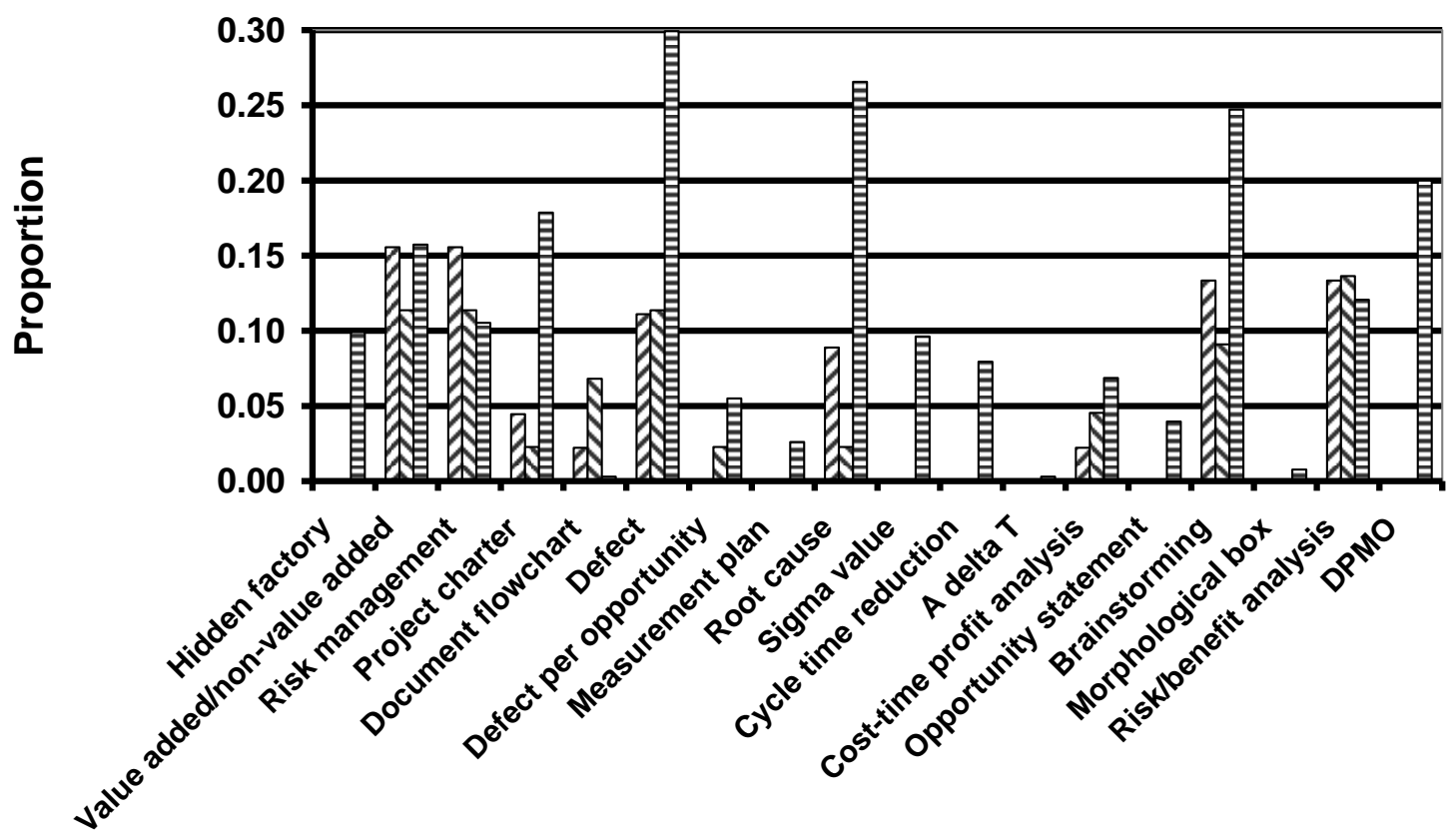

Characteristic

$\square$ SA\&D $\triangle$ AIS $\boxminus$ Six Sigma

Figure 4: Individual characteristic comparison

Among those with low inclusion, a number of surprises occurred for the Six Sigma content. Six Sigma characteristics that experienced a very low result based on the application of these tools by major businesses $[6,7,8,9,10]$ are as follows:

- Document flowchart

- Defect per opportunity

- Measurement plan

- A delta T

- Morphological box

The defect characteristic produced a surprise. While it had the highest proportion of all characteristics in Six Sigma textbooks, its companion characteristic of defect per opportunity occurred far less than is indicated by the proportion of the DPMO characteristic. The characteristic of document flowchart has a lower proportion than either SA\&D or AIS. This is unusual because document flowcharts are a key tool used in assessing a hidden factory and non-value added processes, and they have been an accepted SA\&D analysis tool for a long time [16]. Also, A delta T supports the determination of non-value added processes. This had a very low proportion in Six Sigma textbooks and did not register for SA\&D and AIS.
The assessment of the individual Six Sigma characteristics indicates there are major opportunities available to include Six Sigma tools in SA\&D and AIS courses. The facts show that a number of important characteristics in Six Sigma are missing from those textbooks. This reinforces the opportunity for SA\&D and AIS courses to include Six Sigma business problem solving within these courses.

\section{CONCLUSION}

Six Sigma is a broadly accepted methodology for approaching a wide scope of business problems, including those which may lead to an IT solution. The methodology shares a number of problem solving techniques and methods with prior approaches to IT problem solving. However, Six Sigma is more business problem centric with the process driven by a business area team, rather than an IT project team. Six Sigma and traditional IT project methods appear to be compatible. Both Six Sigma project teams and IT project teams can learn from each other as their methodologies continue to evolve. That is, these methods are complimentary and not mutually exclusive. A number of Six Sigma tools align with the content of SA\&D and AIS courses. However, the 
textbooks, and by extension the SA\&D and AIS courses do not include many commonly used Six Sigma tools. Therefore, authors of future SA\&D and AIS textbook should expand their inclusion of the Six Sigma methodology and its accompanying tool set. This should then support a Six Sigma linkage with the courses. Although some association may exist, it is important to provide a more robust alignment with the commonly accepted Six Sigma tools. The result is expected to be future systems analysts who are better prepared for Six Sigma projects, as well as, traditional IT projects. This does not appear to be a huge change in direction. However, such an alignment can lead to important gains in the overall approach to business problem solving.

Future research should examine additional Six Sigma situations that result in IT solutions to illuminate the synergy among the techniques of these business problem solving approaches. That research may also expand the list of characteristics and assess that list's match among the three categories examined herein. Future IT education of entry level systems analyst should consider the tools and methodology of Six Sigma, especially in those areas where many similarities already occur.

\section{REFERENCES}

1. Antony, J. (2007), Is Six Sigma a management fad or fact? Assembly Automation, Vol. 27 No.1, pp.17-19.

2. Antony, J., Kumar, M., Madu, C.N. (2005a), Six Sigma in small and medium sized UK manufacturing enterprises: some empirical observations, International Journal of Quality \& Reliability Management, Vol. 22 No.8, pp.860-74.

3. Antony, J., Kumar, M., Tiwari, M.K. (2005b), An application of Six Sigma methodology to reduce the engine overheating problem in an automotive company, IMechE - Part B, Vol. 219 No.B8, pp.633-46.

4. Benedetto, A.R. (2003). Adapting manufacturing-based six sigma methodology to the service environment of a radiology film library. Journal of Healthcare Management, 48(4), 263-80.

5. Douglas, P. C., Erwin, J. (2000). Six Sigma's focus on total customer satisfaction. The Journal of Quality and Participation, 23(2), 45.
6. Dow. (2003). Dow Six Sigma black belt certification - Orientation. Midland, MI: The Dow Chemical Company.

7. Dow. (2004a). Dow Six Sigma black belt certification - Measure. Midland, MI: The Dow Chemical Company.

8. Dow. (2004b). Dow Six Sigma black belt certification - Analyze. Midland, MI: The Dow Chemical Company.

9. Dow. (2004c). Dow Six Sigma black belt certification - Improve. Midland, MI: The Dow Chemical Company.

10. Dow. (2004d). Dow Six Sigma black belt certification - Control. Midland, MI: The Dow Chemical Company.

11. Drickhamer, D. (2006, March). Mail Flow. Material Handling Management, 61(3), 26-28,30,32,34.

12. Glover, J.D. and Sarma, M.S. (2002) Power System Analysis and Design. Pacific Grove, CA : Wadsworth/Thomson Learning.

13. Hayen, R.L. (2008) Six sigma information systems: a payroll application. Issues in Information Systems, 9(2), 480-488.

14. Hsieh, C.T., Lin, B., Manduca, B. (2007). Information technology and six sigma. The Journal of Computer Information Systems, 47(4), 1-10.

15. Riebling, N.B., Condon, S., Gopen, D. (2004, November). Toward error free lab work. ASQ Six Sigma Forum Magazine, 4(1), 2329.

16. Sauter, V. (2008) IS 6840 -- Information Systems Analysis, Section G01 Syllabus -- Fall, 2008. Retrieved April 3, 2009 from http://www.umsl.edu/ sauterv/analysis/is6840. html.

17. Semprevivo, P. C. (1976). Systems analysis: Definition, process, and design. Chicago: SRA.

18. Siau, K. (2007). Course Syllabus, Management 454/854, Information Systems Analysis and Design. Retrieved April 4, 2009 from http:// www.cba.unl.edu/outreach/unl-ibm/documents/ iSeries454.pdf.

19. Stone, B. (2008, March 28). Amazon.com Inc. New York Times.

20. Sustain the Gain. (2006, November). Health Management Technology, 27(11), 28-31. 